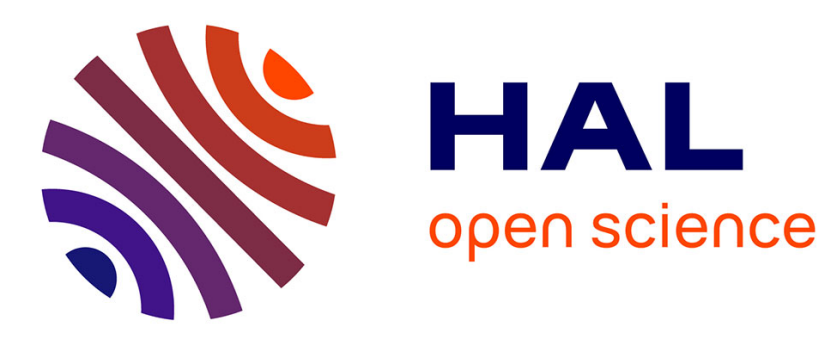

\title{
Modelling of voiced sounds production using a modified two-mass model
}

\author{
Xavier Pelorson, A. Hirschberg, Yves Aurégan
}

\section{To cite this version:}

Xavier Pelorson, A. Hirschberg, Yves Aurégan. Modelling of voiced sounds production using a modified two-mass model. Journal de Physique IV Proceedings, 1994, 04 (C5), pp.C5-453-C5-456. 10.1051/jp4:1994594 . jpa-00253089

\section{HAL Id: jpa-00253089 https://hal.science/jpa-00253089}

Submitted on 1 Jan 1994

HAL is a multi-disciplinary open access archive for the deposit and dissemination of scientific research documents, whether they are published or not. The documents may come from teaching and research institutions in France or abroad, or from public or private research centers.
L'archive ouverte pluridisciplinaire HAL, est destinée au dépôt et à la diffusion de documents scientifiques de niveau recherche, publiés ou non, émanant des établissements d'enseignement et de recherche français ou étrangers, des laboratoires publics ou privés. 


\title{
Modelling of voiced sounds production using a modified two-mass model
}

\author{
X. PELORSON, A. HIRSCHBERG* and Y. AUREGAN**
}

Institut de la Communication Parlée, URA 368 du CNRS, 46 avenue F. Viallet, 38031 Grenoble cedex, France

* Vakgroep Transportfysica, Eindhoven University of Technology, P.O. Box 513, 5600 MB Eindhoven, The Netherlands

** Laboratoire d'Acoustique de l'Université du Maine, Avenue Olivier Messiaen, BP. 535, 72017 Le Mans, France

\begin{abstract}
.
The two-mass model is very often presented as a simple but efficient model quite well adapted for the purpose of voiced sounds numerical simulation. It appear however that the description of the flow through the glottis is usually oversimplified. To some extent this point could explain the limits of the model. This paper proposes a more precise description of the flow through the glottis. In particular a quasi-steady moving flow separation point is introduced. A validation of the theory under unsteady-flow conditions is presented here. The importance of the revised flow model for phonation modelling is evaluated and discussed using a simple model for the vocal cords based on the well-known two-mass model.
\end{abstract}

\section{Introduction}

Modelling of voiced sounds production requires both a model for the mechanics of the vocal cords and a model for the air flow through the glottis. Most models presented in the literature [1-4] are in fact introducing improvements of the mechanical description. However, the fluid mechanics remains usually extremely simplified. Our aim is not to propose another model but to try to improve existing models by a more realistic flow description. We thus present a revised flow model which is compared to Ishizaka and Flanagan flow model. The validation of the proposed theory is done using unsteady-flow in-vitro experiments. In order to evaluate the effective importance of the revised flow model, an application to a simple mechanical model for the vocal cords is then presented.

\section{Revised flow theory.}

We present here a comparison between the proposed revised flow theory and the flow model proposed by Ishizaka et al. [2] (I\&F model), which is the most commonly used flow model.

\begin{tabular}{|l|l|}
\hline \multicolumn{1}{|c|}{ I\&F model } & \multicolumn{1}{c|}{ Proposed model } \\
\hline $\begin{array}{l}\text { - Flow separation at the entrance of } \\
\text { the glottis } \\
\text { (vena contracta) }\end{array}$ & $\begin{array}{l}\text { - Smooth, rounded and progressive } \\
\text { entrance } \\
\text { (no losses) }\end{array}$ \\
\hline - Fixed separation point & - Quasi-steady separation point \\
\hline - Pressure recovery model & - Pressure recovery neglected \\
\hline
\end{tabular}

Table I : Comparison between the proposed flow model and Ishizaka et al. flow description.

The first point of table I refers to the behaviour of the flow at the glottal entrance. In I\&F description, it is assumed that flow separation takes place (vena contracta effect) and that strong pressure losses are induced ( $37 \%$ of the initial pressure). In fact, the vena contracta effect is known to occur at a discontinuity with sharp edges [5]. Since the glottal entrance is rounded (and progressive) we do not consider such effect to be relevant. The second point refers to the occurrence of flow separation within the glottal channel. This point is particularly important during the closing phase where the glottis forms a diverging channel. In such a case, the flow model of Ishizaka et al. implicitly assumes that flow separation takes place at a fixed position (the end of the glottal channel). In the proposed flow model, we consider the possibility of a moving flow 
separation point. Prediction of flow separation's position is done using a simplified boundary-layer model $[6,7]$.

Finally, the last point concerns the behaviour of the glottal flow after flow separation has occurred. In the I\&F model a quasi-steady reattachment of the flow is assumed. Because the quasi-steady assumption doesn't seem fully consistent in such a case and because the pressure recovery in I\&F is almost negligible, we simply do not consider any pressure recovery effect.

\section{I.2. Experimental validation.}

Several different experiments were performed in order to test the validity of the revised theory $[6,7,8]$. In this paper only unsteady-flow experiments are presented.

\subsubsection{Experimental set-up.}

The experimental set-up is depicted in figure 1. It consists into a glottal model made about three times larger than physiological size, placed at the end of a reservoir. The unsteady flow conditions were performed by impulsively opening a dynamic valve. Due to the typical Strouhal numbers involved $\left(\mathrm{Sr}=\mathrm{O}\left(10^{-2}\right)\right)$, we expect the unsteady effects to be comparable to those encountered during phonation .

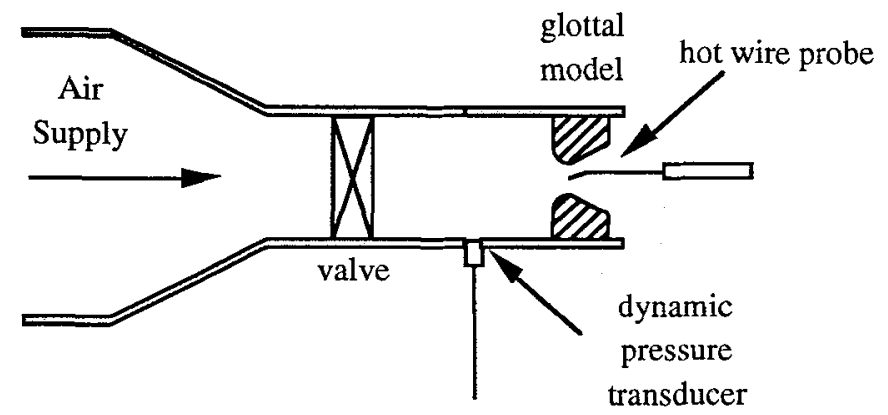

Figure 1 : Experimental set-up used during unsteady flow measurements.

Dynamic pressure measurements have been done using acceleration compensated piezo-electrical gauges (PC116A) while local flow velocity was measured using a hot wire.

\section{I.2.2. Mean flow prediction.}

The glottal model used consisted into a straight channel with a rounded entrance. As flow separation is imposed to occur at the sharp edged outlet, this model allows the validation of the mean flow prediction (and in particular of the occurrence of a vena contracta effect at the entrance of the glottis). Figure 2(a) presents an example of the time-dependent pressure difference imposed on the glottal model.

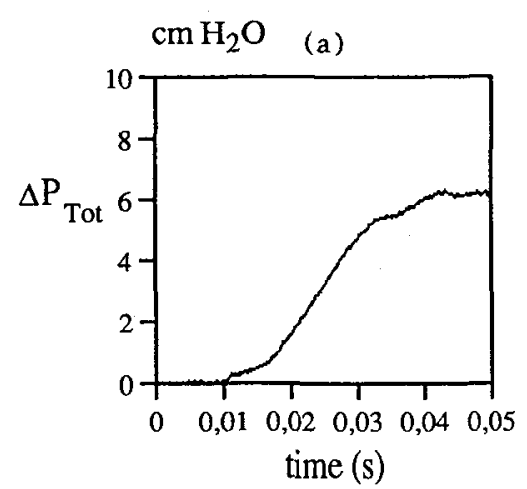

$$
\mathrm{m} . \mathrm{s}^{-1}
$$

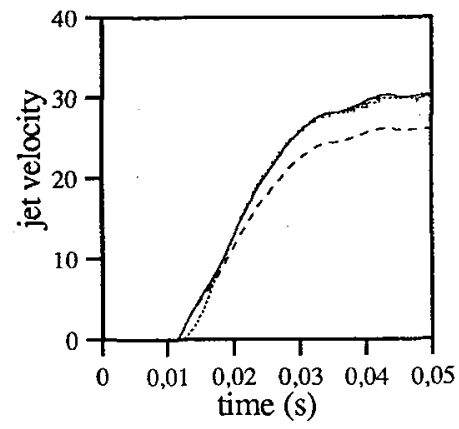

measured velocity proposed theory I\&F theory

Figure 2: (a) Time dependent pressure difference imposed on the model. (b) Comparison between measured flow velocity at the outlet of the glottal channel (dotted line) and theoretical expectation derived from the pressure signal using I\&F theory (dashed line) and present theory (solid line).

In figure 2(b) is presented a comparison between the measured flow velocity at separation (jet velocity) and the theoretical expectations inferred from the pressure signal shown in figure 3 (a).

As can be clearly seen assuming a vena contracta effect at the entrance of the glottal channel strongly underestimates the flow velocity. The proposed flow model is in good agreement with the measured data. 
The strongest discrepancies occur for the very first milliseconds. The assumption of a quasi-stationary jet flow after separation is not accurate during this period. Vortices formed during the initialisation of the flow are still very close to the outlet.

\subsubsection{Flow separation prediction.}

The glottal model under test consisted into a diverging channel with rounded entrance. The angles of divergence studied were: $\alpha=10^{\circ}$ and $\alpha=20^{\circ}$. As an example of results figure $3(\mathrm{a})$ presents the pressure difference imposed on the model for $\alpha=20^{\circ}$, and figure 3(b) compares the measured flow at the throat with the theoretical expectation.
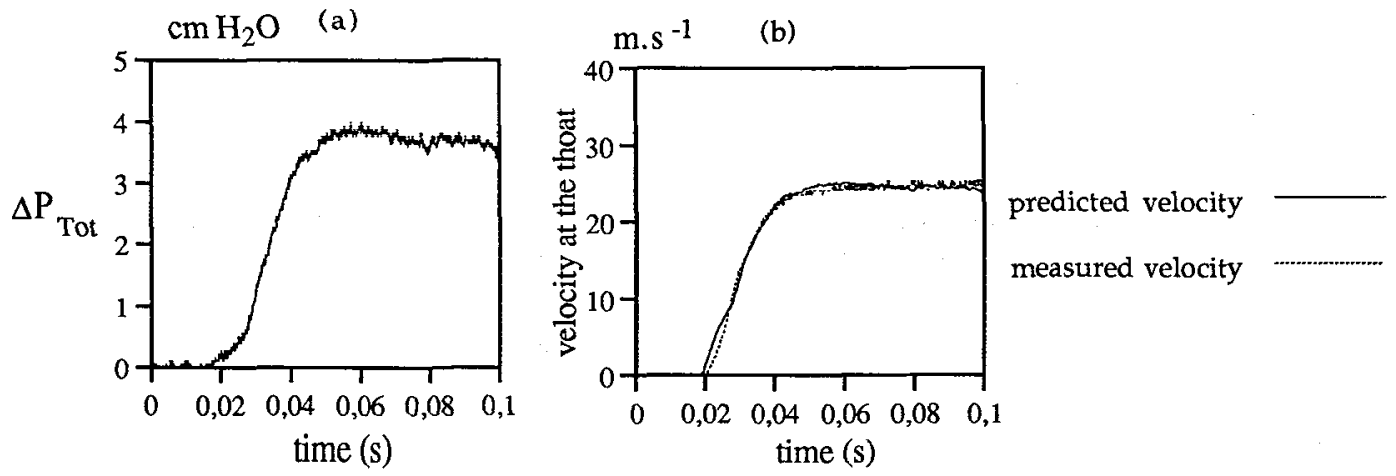

Figure 3 : (a) Time dependent pressure difference imposed on the diverging glottal model. (b) Comparison between measured flow velocity at the throat of the diverging glottal channel (dotted line) and theoretical expectation inferred from the pressure signal (solid line).

\subsection{Conclusions.}

The results presented here reveal a good accuracy for both the mean flow prediction (section I.2.2) and the prediction of the flow separation point (section I.2.3). These experiments also confirmed that a vena contracta effect is certainly not relevant when it complies with a rounded entrance, like the entrance of the glottis.

\section{Application to a numerical model.}

\section{III.1. Description of the model.}

We chose for simplicity, to study the most simple vocal cord description : the two-mass model as proposed by Ishisaka et al. [2]. In Ishizaka's model, the shape of the vocal cords is determined by rectangular masses, such a description is certainly not suitable for implementing a moving flow separation position since flow separation would always occur at the sharp edges of the model. The proposed model is based on the same simple mechanical description as the two-mass model but for which the movement of the two masses are used as control parameters of a smooth surface as shown in figure 4.

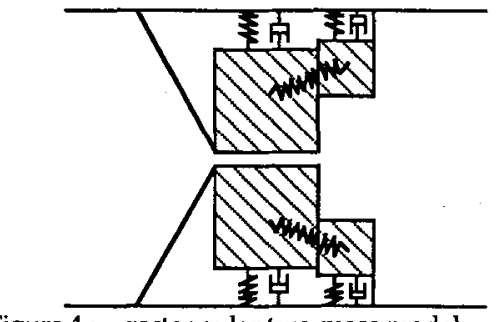

Figure 4: rectangular two-mass model.

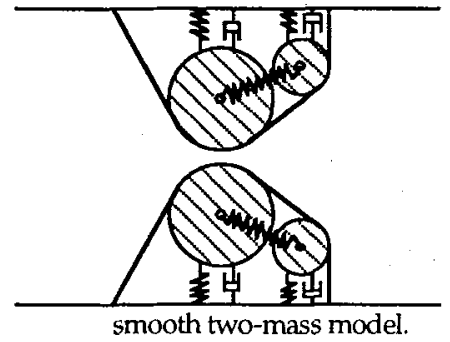

III.2. Simulation results.

Several simulations and comparisons between the proposed model and the model of Ishizaka et al.[2] were performed. The major results can be summarized as follows :

- The predicted peak flows are strongly different from one model to the other. This effect is mainly due to the assumption of a vena contracta. As a matter of fact, assuming a vena contracta at the entrance of the glottal channel does not only underestimates the velocity itself (see figure 3 ) but also has consequences on the mechanical model through the pressure forces. 
- a moving flow separation has significant influence on numerical results. When implemented, this effect does not only reduce the fundamental frequency but also affects the glottal waveforms. In particular the very strong and unrealistic negative peak flows of the time derivative volume velocity, which are typical of the rectangular two-mass model, are much more less pronounced with the proposed model as shown in figure 5.
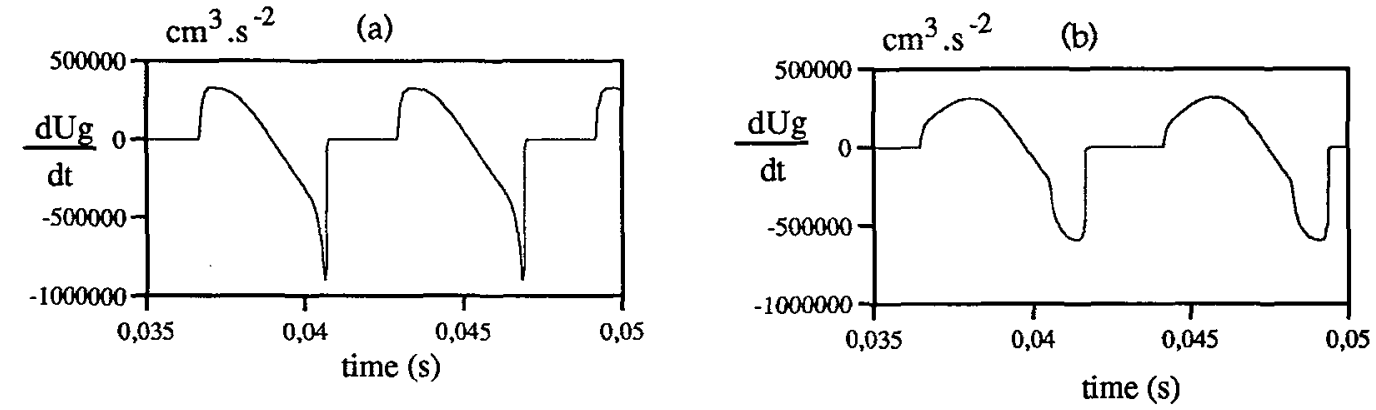

Figure 5: Time-derivative of the glottal volume velocity obtained using (a) rectangular two-mass model with I\&F flow model, (b) smooth model cords coupled with the revised flow theory.

- the use of a smooth-shaped model also allows a more realistic description of the vocal cords collision as well as some three-dimensional effects can be easily taken into account. For instance, the zip-like closure of the glottis can be described by assuming a mechanical contact prior to the glottis closure. Figure 6 is an example of results obtained using such a model.
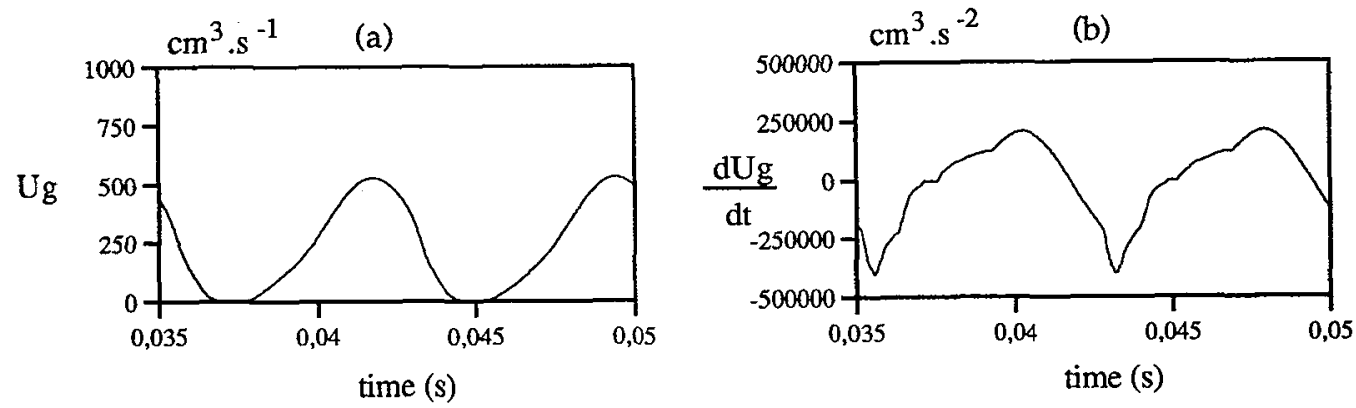

Figure 6 : (a) Glottal volume velocity and (b) corresponding time derivative obtained using a collision model.

The result presented in figure 6 is interesting since it presents glottal waveforms that can hardly be obtained with Ishizaka et al. model but appears to be realistic when compared with signals obtained by inverse filtering techniques.

\section{Acknowledgements.}

This work was supported by the Dutch Foundation for Fundamental Research on Matter (FOM) (grant SWd/E4 ) and the European Esprit project SPEECH MAPS.

\section{References :}

[1] Flanagan J.L, Landgraf L,L. (1967). "Self-oscillating Source for Vocal-Tract Synthesizers", Proc. IEEEAFCRL. Symposium on Speech Commun. and Process., Boston Mass.

[2] Ishizaka K, Flanagan J.L (1972). "Synthesis of Voiced Sounds from a Two-Mass Model of the Vocal Cords", B.S.T.J., 51, pp 1233-1268.

[3] Descout R,Auloge J,Y, Guerin B (1980). "Continuous model of the vocal source", Proc. ICA-SSP pp 61-64.

[4] Titze, I.R (1973). "The human vocal cords : A mathematical Model part I", Phonetica, 28, pp 129-170.

[5] Blevins R.D (1984). "Applied Fluid Dynamic Handbook", Van Nostrand Reinhold Co. : New York.

[6] Pelorson X., Hirschberg A., van Hassel R.R., Wijnands A.P.J, Auregan Y. (1993). "Theoretical and Experimental Study of Quasi-Steady Flow Separation within the Glottis during Phonation. Application to a modified two-mass model", IPO report $\mathrm{N}^{\circ}$ 952, Institute, for Perception Research, Eindhoven.

[7] Pelorson X., Hirschberg A., Auregan Y. (1993). "Modified two-mass model for the vocal cords", J. Acoust. Soc. Am., 93, 5aSP15.

[8] Pelorson X., Hirschberg A., Auregan Y., Baillet H. (1993). "Fluid dynamics aspects of speech. 1) Modified two mass model", Stockholm Musics Acoustics Conference '93, to appear in proceedings. 